\title{
Caracterização da farinha de banana verde
}

\author{
Green banana flour characterization
}

\section{Antonia de Maria BORGES ${ }^{1 *}$, Joelma PEREIRA² ${ }^{2}$ Eliseu Marlônio Pereira de LUCENA ${ }^{3}$}

\begin{abstract}
Resumo
O presente trabalho objetivou a obtenção, a caracterização físico-química e o controle microbiológico durante o processamento da farinha de banana (Musa spp.) verde, cv. Prata, visando o seu aproveitamento na panificação, produtos dietéticos e alimentos infantis. Para obtenção da farinha, os frutos foram cortados, imersos em metabissulfito de sódio, desidratados e triturados, sendo em seguida, feitas as seguintes determinações: umidade; extrato etéreo; proteína bruta; fibra bruta; cinzas; fração glicídica; amido; valor calórico; $\mathrm{pH}$; acidez total titulável; vitamina C; macrominerais (K, P, Ca, Mg, S e N); microminerais (B, Cu, Mn, Zn e Fe); coliformes a $45^{\circ} \mathrm{C}$; fungos filamentosos e leveduras; Bacillus cereus; Salmonella sp.; Staphylococcus aureus; e contagem de aeróbios mesófilos. Os resultados indicaram que a banana 'Prata' verde é viável para o processo de obtenção da farinha de banana, tendo em vista que é rica em amido, proteína, potássio, fósforo, magnésio, zinco, cobre e tem um alto valor calórico. $\mathrm{O}$ pH, a acidez total titulável e a vitamina $\mathrm{C}$ estão compatíveis com os valores encontrados em outras farinhas. Quanto ao uso de boas práticas no processamento, a farinha encontra-se dentro do padrão microbiológico ideal e, portanto, está apta para o consumo.
\end{abstract}

Palavras-chave: Musa spp.; Prata; panificação; composição centesimal; físico-química; microbiológica.

\begin{abstract}
The objective of the present study was the physicochemical characterization and the microbiological control during the processing of the green banana flour (Musa spp.), Prata cultivar, aiming at the use of the flour in bread-making, dietary products and children's food. To obtain the flour, the fruits were cut, immersed in sodium meta-bisulfite, dehydrated, and ground. The following criteria were determined: humidity; ethereal extract; raw protein; raw fiber; ash; glicidic fraction; starch; caloric value; $\mathrm{pH}$; total titratable acidity; vitamin $\mathrm{C}$; macrominerals (K, $\mathrm{P}$, $\mathrm{Ca}, \mathrm{Mg}, \mathrm{S}$ and $\mathrm{N}$ ); microminerals (B, Cu, Mn, Zn and Fe); coliforms at $45^{\circ} \mathrm{C}$; filamentous fungi and yeast; Bacillus cereus; Salmonella sp.; Staphylococcus aureus; and the quantitative counting of aerobic mesofile. The results indicated that the process for the production of banana flour is viable for Prata green banana due to its rich content of starch, protein, potassium, phosphorus, magnesium, zinc, copper, and high caloric value. The $\mathrm{pH}$, the total titratable acidity and the vitamin $\mathrm{C}$ are compatible with the values found in other flours. The flour obtained using the process in this study presented ideal microbiological pattern and, therefore, is appropriate for the human consumption.
\end{abstract}

Keywords: Musa spp.; Prata; bakery; centesimal composition; physicochemical; microbiological.

\section{Introdução}

A banana é uma das frutas mais consumidas no mundo, sendo produzida na maioria dos países tropicais (SOUSA et al., 2003), representa a quarta fonte de energia depois do milho, arroz e trigo. Sua alta concentração de amido a partir do processamento em farinha é de interesse como fonte alimentar e propósito industrial. Em países como o Brasil e a Venezuela, onde se consome muito trigo importado, este pode ser mesclado com outros cereais e vegetais com alto conteúdo de amido como fontes de nutrientes com menos custos (PACHECO-DELAHAYE; TESTA, 2005).

Segundo Adão e Glória (2005), a banana possui variável fonte de minerais, sendo um importante componente na alimentação em todo o mundo. Seu sabor é um dos mais importantes atributos de qualidade, a polpa verde é caracterizada por uma forte adstringência determinada pela presença de compostos fenólicos solúveis, principalmente taninos. À medida que a banana amadurece, ocorre polimerização desses compostos, com consequente diminuição na adstringência, aumento da doçura e redução da acidez (VILAS BOAS et al., 2001).

Conforme o Sistema Brasileiro de Respostas Técnicas SBRT (2006), as farinhas de bananas podem ser obtidas de secagem natural ou artificial, através de bananas verdes ou semiverdes das variedades, Prata, Terra, Cavendish, Nanica ou Nanicão. Quando bem processadas podem ser utilizadas em panificação e alimentos infantis. Sua qualidade depende de vários fatores incluindo matéria-prima, método de secagem, técnicas de procedimentos e forma de armazenamento.

Segundo Loures (1989), instalações de fábricas de farinha de médio e pequeno porte podem ser localizadas próximas às fontes de alimento in natura a fim de estimular a agricultura, implantar novas indústrias alimentícias e favorecer criação de novos empregos, promovendo assim o aumento de renda per capita.

Recebido para publicação em 15/11/2007

Aceito para publicação em 28/10/2008 (002871)

1 Tecnologia de Alimentos, Faculdade de Tecnologia Centec Cariri-FATEC, Rua Amália Xavier de Oliveira, s/n, Triângulo, CEP 63040-000, Juazeiro do Norte - CE, Brasil, E-mail: antoniaborgesborges@yahoo.com.br

2 Departamento de Ciências dos Alimentos, Universidade Federal de Lavras - UFLA, Campus Histórico, CP 3037, CEP 37200-000, Lavras - MG, Brasil, E-mail: joper@ufla.br ${ }^{3}$ Ciências Biológicas, Universidade Estadual do Ceará - UECE, Av. Paranjana, 1700, Itaperi, CEP 60740-903, Fortaleza - CE, Brasil, E-mail: eliseulucena@uece.br

${ }^{*}$ A quem a correspondência deve ser enviada 
A produção de farinhas apresenta grande variabilidade para a indústria de alimentos, principalmente em produtos de panificação, produtos dietéticos e alimentos infantis, por serem rica fonte de amido e sais minerais (CARVALHO, 2000).

O presente trabalho objetivou a obtenção, a caracterização físico-química e o controle microbiológico durante o processamento da farinha de banana verde da cultivar Prata, visando o seu aproveitamento na panificação, produtos dietéticos e alimentos infantis.

\section{Material e métodos}

\subsection{Local do ensaio}

Este trabalho foi conduzido na Faculdade de Tecnologia Centec Cariri - FATEC, no Núcleo de Tecnologia do Estado do Ceará - NUTEC e no Laboratório de Ciência e Tecnologia de Alimentos da Universidade Federal de Lavras - UFLA, durante o período de agosto de 2006 a fevereiro de 2007.

\subsection{Obtenção da farinha de banana verde}

A cultivar utilizada para obtenção da farinha de banana verde foi a cultivar Prata, proveniente do mercado Pirajá da Cidade do Juazeiro do Norte - CE. Foram pesadas 954 bananas com casca, equivalentes a $86,93 \mathrm{~kg}$ de bananas. Foram lavadas com água corrente, imersas em água clorada a 150 ppm por 15 minutos e descascadas manualmente com faca de aço inox, sendo obtidos $17,02 \mathrm{~kg}$ de bananas sem cascas. As bananas foram cortadas em rodelas de $0,5 \mathrm{~cm}$ de espessura, imersas em metabissulfito de sódio 2 ppm por 15 minutos, desidratadas em estufa de circulação de ar forçado a $70^{\circ} \mathrm{C}$ por 12 horas, trituradas em moinho de martelo e obtidos 12,680 kg de farinha de banana verde. A farinha foi acondicionada em potes plásticos de polipropileno com capacidade de $700 \mathrm{~g}$. Finalmente, foram retiradas amostras para análises físico-químicas e microbiológicas com 5 repetições.

\subsection{Umidade (U)}

A umidade foi determinada através do método gravimétrico com emprego de calor, baseando-se na perda de peso do material submetido ao aquecimento em estufa a $105^{\circ} \mathrm{C}$ até peso constante segundo a metodologia da AOAC (1995).

\subsection{Extrato etéreo (EE)}

O extrato etéreo da farinha de banana foi determinado segundo o método de Soxlet, utilizando hexano como solvente orgânico (AOAC, 1995).

\subsection{Proteína bruta $(P B)$}

A proteína bruta foi obtida pela determinação da porcentagem de nitrogênio total da amostra segundo o método de Kjeldahl (AOAC, 1995) e multiplicação pelo fator 6,25.

\subsection{Fibra bruta (FB)}

A fibra bruta foi determinada pelo método gravimétrico de Kamer e Ginkel (1952).

\subsection{Cinzas (C)}

O resíduo mineral fixo (cinzas) foi determinado por incineração do material em mufla regulada a $550{ }^{\circ} \mathrm{C}$ até peso constante, segundo método da AOAC (1995).

\subsection{Fração glicídica (FG)}

O método utilizado foi o cálculo por diferença segundo a Equação 1, na qual foi considerada a matéria integral e o resultado foi expresso em g. $100 \mathrm{~g}^{-1}$ na base úmida, conforme o método da AOAC (1995).

$\mathrm{FG}=100-(\mathrm{U}+\mathrm{EE}+\mathrm{PB}+\mathrm{FB}+\mathrm{C})$

em que:

$$
\begin{aligned}
& \mathrm{FG}=\text { fração glicídica }\left(\mathrm{g} .100 \mathrm{~g}^{-1}\right) ; \\
& \mathrm{U}=\text { umidade }\left(\mathrm{g} .100 \mathrm{~g}^{-1}\right) ; \\
& \mathrm{EE}=\text { extrato etéreo }\left(\mathrm{g} .100 \mathrm{~g}^{-1}\right) ; \\
& \mathrm{PB}=\text { proteína bruta }\left(\mathrm{g} .100 \mathrm{~g}^{-1}\right) ; \\
& \mathrm{FB}=\text { fibra bruta }\left(\mathrm{g} .100 \mathrm{~g}^{-1}\right) ; \mathrm{e} \\
& C=\text { cinzas }\left(\mathrm{g} .100 \mathrm{~g}^{-1}\right) .
\end{aligned}
$$

\subsection{Amido}

O teor de amido foi determinado conforme metodologia descrita em AOAC (1995), com algumas adaptações. Sendo assim, determinaram-se os açúcares redutores pelo método do DNS (ácido dinitrosalicílico), conforme Miller (1959). As leituras foram feitas em espectrofotômetro, a $540 \mathrm{~nm}$. Os resultados obtidos foram multiplicados pelo fator 0,90 para a obtenção do amido em $\mathrm{g} .100 \mathrm{~g}^{-1}$ na base úmida.

\subsection{Valor calórico}

Foi efetuado com base na composição da farinha, utilizando os fatores de conversão de Atwater: 4 kcal.g ${ }^{-1}$ (proteínas), 4 kcal.g-1 ( carboidratos) e 9 kcal.g ${ }^{-1}$ (lipídios), conforme Osborne e Voogt (1978).

\section{$2.11 \mathrm{pH}$}

$\mathrm{O}$ pH foi determinado em pHmetro, modelo portátil DM pH-2, Hanna Instruments, com inserção do eletrodo diretamente na farinha diluída em 100 mL de água destilada (IAL, 1985).

\subsection{Acidez total titulável}

A acidez total titulável (ATT) foi medida por titulação do filtrado com $\mathrm{NaOH}$ 0,1 N padronizado segundo técnica estabelecida pelas normas do Instituto Adolfo Lutz (1985) e os resultados expressos em $\mathrm{mL}$ de $\mathrm{NaOH}$ gastos na titulação.

\subsection{Vitamina $C$}

O conteúdo de ácido ascórbico (após a oxidação a ácido dehidroascórbico) foi determinado pelo método 2,6 diclorofenol indofenol segundo Pearson (1971). A leitura foi realizada em espectrofotômetro a $520 \mathrm{~nm}$. Os resultados foram expressos em mg. $100 \mathrm{~g}^{-1}$ de massa fresca. 


\subsection{Composição de minerais}

Determinaram-se os macrominerais ( $\mathrm{P}, \mathrm{Ca}, \mathrm{Mg}, \mathrm{S}$ e $\mathrm{N}$ ) e microminerais ( $\mathrm{B}, \mathrm{Cu}, \mathrm{Mn}, \mathrm{Zn}$ e Fe) da farinha de banana verde, cultivar Prata, através de espectrofotometria de absorção atômica com chama de acetileno, enquanto o potássio foi determinado por fotometria de chama, conforme a metodologia estabelecida por Sarruge e Haag (1974) e Malavolta et al. (1989).

\subsection{Análises microbiológicas}

Foram realizadas análises de coliformes a $45^{\circ} \mathrm{C}$, fungos filamentosos e leveduras, Bacillus cereus, Salmonella sp., Staphylococcus aureus e contagem de aeróbios mesófilos na farinha de banana verde, segundo as metodologias propostas pela APHA (2001).

As amostras de farinha de banana verde foram coletadas com cinco repetições. Foram coletadas $25 \mathrm{~g}$ de amostra para cada análise e colocadas em solução salina em água peptonada ( $0,1 \%)$, estéril; posteriormente foram feitas as diluições seriadas para inoculação dos diferentes meios de cultura utilizados no experimento.

\section{Resultados e discussão}

\subsection{Composição centesimal}

A composição centesimal (umidade, extrato etéreo, proteína bruta, fibra bruta, cinzas e fração glicídica), o teor de amido e o valor calórico da farinha de banana verde encontram-se na Tabela 1.

Verifica-se na Tabela 1 que o teor de umidade encontrado na farinha de banana verde foi 3,30 g. $100 \mathrm{~g}^{-1}$ e encontra-se dentro do padrão ANVISA (1978) que exige o máximo de 15 g. $100 \mathrm{~g}^{-1}$ de umidade em farinhas.

Moraes Neto et al. (1998), em experimento com banana (Musa spp.), cv. Prata, encontraram 7,20 g.100 g-1 de umidade em farinha de banana verde em secagem solar por 18 horas.

De acordo com Damiani (1989) em experimento com farinha de banana do subgrupo Cavendish utilizada em formulação de mingaus, detectara-se 9,77 g.100 g-1 de umidade; valor este superior ao encontrado neste trabalho.

Tabela 1. Valores médios da umidade, extrato etéreo, proteína bruta, fibra bruta, cinzas, fração glicídica, amido e valor calórico da farinha de banana verde, cv. Prata.

\begin{tabular}{|c|c|c|}
\hline \multirow[t]{2}{*}{ Variáveis } & \multicolumn{2}{|c|}{ Base } \\
\hline & Úmida (b.u.) & Seca (b.s.) \\
\hline Umidade (g.100 g $\left.\mathrm{g}^{-1}\right)$ & $3,30 \pm 0,08$ & - \\
\hline Extrato etéreo $\left(\mathrm{g} .100 \mathrm{~g}^{-1}\right)$ & $0,68 \pm 0,03$ & $0,70 \pm 0,03$ \\
\hline Proteína bruta $\left(\mathrm{g} .100 \mathrm{~g}^{-1}\right)$ & $4,50 \pm 0,84$ & $4,73 \pm 0,84$ \\
\hline Fibra bruta (g.100 g-1) & $1,01 \pm 0,02$ & $1,17 \pm 0,02$ \\
\hline Cinzas $\left(\mathrm{g} .100 \mathrm{~g}^{-1}\right)$ & $2,59 \pm 0,07$ & $2,68 \pm 0,07$ \\
\hline Fração glicídica (g.100 g $\left.{ }^{-1}\right)$ & $87,92 \pm 0,91$ & $90,72 \pm 0,91$ \\
\hline Amido (g.100 g $\left.{ }^{-1}\right)$ & $72,72 \pm 0,47$ & $75,20 \pm 0,47$ \\
\hline Valor calórico $\left(\mathrm{kcal} .100 \mathrm{~g}^{-1}\right)$ & $373,00 \pm 0,75$ & $385,30 \pm 0,75$ \\
\hline
\end{tabular}

Cada valor foi obtido por meio da média \pm desvio padrão de cinco repetições.
O valor médio de extrato etéreo obtido neste trabalho foi $0,68 \mathrm{~g} .100 \mathrm{~g}^{-1}$, valor semelhante ao encontrado por Torres et al. (2005), que constataram um valor de $0,53 \mathrm{~g} .100 \mathrm{~g}^{-1}$ em farinha de banana (Musa acuminata) verde utilizada em produtos extrusados. Por outro lado, Damiani (1989) encontrou na farinha de banana verde do subgrupo Cavendish apenas um valor de $0,18 \mathrm{~g} .100 \mathrm{~g}^{-1}$ de extrato etéreo, que é bastante inferior ao valor encontrado nesta pesquisa.

Quanto ao teor de proteína bruta encontrado neste trabalho, foi 4,5 g.100 g-1. Neste sentido, Moraes Neto et al. (1998), estudando esta mesma cultivar, encontraram valores médios de 3,2 g. $100 \mathrm{~g}^{-1}$ em farinha de banana verde.

Para fibra bruta, o valor médio encontrado foi $1,01 \mathrm{~g} .100 \mathrm{~g}^{-1}, \mathrm{o}$ qual é inferior ao verificado por Fernandes (2006) quando estudou a composição da farinha de casca da batata $\left(1,62 \mathrm{~g} \cdot 100 \mathrm{~g}^{-1}\right)$.

Quanto às cinzas, o valor médio encontrado neste trabalho foi 2,59 g. $100 \mathrm{~g}^{-1}$. Já Moraes Neto et al. (1998), com esta mesma cultivar, encontraram 4,14 g. $100 \mathrm{~g}^{-1}$; no entanto, Torres et al. (2005) encontraram $2 \mathrm{~g} .100 \mathrm{~g}^{-1} \mathrm{em}$ farinha de banana verde, cv. Nanicão.

O valor médio da fração glicídica neste trabalho foi 87,92 g. $100 \mathrm{~g}^{-1}$, que se assemelha com os resultados encontrados por Torres et al. (2005), quando observaram 91,70 g. $100 \mathrm{~g}^{-1} \mathrm{em}$ farinha de banana 'Nanicão' verde, mas difere dos resultados de Damiani (1989), pois este verificou apenas 76,71 g.100 g $\mathrm{g}^{-1}$ na farinha de banana verde do subgrupo Cavendish.

O teor de amido encontrado nesta pesquisa foi $72,72 \mathrm{~g} \cdot 100 \mathrm{~g}^{-1}$, portanto corroborado pelos resultados de Damiani (1989) e Oliveira (1997), que encontraram respectivamente 69 e 70 g. $100 \mathrm{~g}^{-1}$ de amido na farinha de banana verde.

Constatou-se na farinha de banana verde analisada neste trabalho um valor calórico médio de $373 \mathrm{kcal} .100 \mathrm{~g}^{-1}$, no entanto, Pereira et al. (2005) encontraram em farinha de batata um valor mais baixo (340 kcal.100 $\mathrm{g}^{-1}$ ).

\subsection{Análises físico-químicas da farinha de banana verde}

$\mathrm{Na}$ Tabela 2 apresentam-se os resultados médios das características físico-químicas (acidez total titulável, $\mathrm{pH}$ e Vitamina C) da farinha de banana verde.

$\mathrm{O}$ valor médio de $\mathrm{pH}$ registrado neste trabalho foi de 5,30. Este comportamento ratifica alguns estudos realizados, tais como, o trabalho realizado por Borba (2005), pois ele constatou na farinha de batata doce um $\mathrm{pH}$ de 5,70 e a pesquisa realizada por Fernandes (2006), o qual estudou a composição da farinha da casca da batata e verificou um $\mathrm{pH}$ de 4,96.

O valor médio da acidez total titulável observado neste experimento foi de $0,63 \mathrm{~g} .100 \mathrm{~g}^{-1}$, no entanto, Chisté et al. (2006), trabalhando com farinha de mandioca, obtiveram um valor bem superior $\left(4,11 \mathrm{~g} .100 \mathrm{~g}^{-1}\right)$. Neste sentido, tendo em vista os efeitos tóxicos sofridos pelos microrganismos, quando estão num $\mathrm{pH}$ desfavorável, isto é, muito ácido, podemos constatar que o $\mathrm{pH}$ ácido $(5,30)$ verificado neste experimento é benéfico ao produto final, pois promove uma maior vida de prateleira para a farinha de banana verde. 
Estes resultados são semelhantes aos constatados por Lucena et al. (2003) quando estudando o uso de etileno exógeno na maturação de banana 'Prata-anã': no estádio 2 de maturação, isto é, verdes, possuíam valores médios de $\mathrm{pH}$ 5,51 e acidez total titulável $0,10 \mathrm{~g} \cdot 100 \mathrm{~g}^{-1}$.

Conforme Fontes (2005), existem dois métodos mais comumente usados para medir a acidez dos alimentos, são a ATT e o $\mathrm{pH}$. O primeiro representa todos os grupamentos ácidos encontrados (ácidos orgânicos livres, na forma de sais e compostos fenólicos), enquanto que o segundo determina a concentração hidrogeniônica da solução.

$\mathrm{O}$ teor médio de vitamina $\mathrm{C}$ evidenciado neste trabalho foi $15,12 \mathrm{mg} \cdot 100 \mathrm{~g}^{-1}$, o que atenderia em parte a necessidade de ingestão diária recomendada (IDR) de vitamina $\mathrm{C}$ para adultos, a qual é de $60 \mathrm{mg}$ (YAMASHITA et al., 2003).

\subsection{Composição de minerais da farinha de banana verde}

As concentrações de potássio, fósforo cálcio, magnésio, enxofre, nitrogênio, boro, cobre, manganês, zinco e ferro encontram-se expressas na Tabela 3.

O valor de potássio detectado neste trabalho foi $1.180 \mathrm{mg} .100 \mathrm{~g}^{-1}$, o que é considerado como uma fonte rica deste mineral, por outro lado, Ascheri et al. (2006) encontraram na farinha de arroz polido apenas $97,22 \mathrm{mg} .100 \mathrm{~g}^{-1}$, portanto, uma fonte pobre deste mineral.

O teor de fósforo registrado neste trabalho foi de $100 \mathrm{mg} .100 \mathrm{~g} \mathrm{~g}^{-1}$, no entanto, Ascheri et al. (2006) trabalhando com farinha de arroz polido encontraram um valor menor de fósforo (77,48 mg.100 g ${ }^{-1}$ ).

O conteúdo médio de cálcio verificado nesta pesquisa foi de $130 \mathrm{mg} .100 \mathrm{~g}^{-1}$. Por outro lado, Medina et al. (1985) afirmam

Tabela 2. Valores médios das características físico-químicas ( $\mathrm{pH}$, acidez total titulável e vitamina C) da farinha de banana verde, cv. Prata.

\begin{tabular}{lc}
\hline \multicolumn{1}{c}{ Variáveis } & Base úmida (b.u.) \\
\hline $\mathrm{pH}$ & $5,30 \pm 0,08$ \\
Acidez total titulável $\left(\mathrm{g} .100 \mathrm{~g} \mathrm{~g}^{-1}\right)$ & $0,63 \pm 0,04$ \\
Vitamina C $\left(\mathrm{mg} .100 \mathrm{~g} \mathrm{~g}^{-1}\right)$ & $15,12 \pm 0,79$ \\
\hline
\end{tabular}

Cada valor foi obtido por meio da média \pm desvio padrão de cinco repetições.

Tabela 3. Teores médios de macro e microminerais da farinha de banana verde, cv. Prata.

\begin{tabular}{cccc}
\hline \multicolumn{5}{c}{ Minerais (base seca) } \\
\hline \multicolumn{3}{c}{ Macro } & \multicolumn{2}{c}{ Micro } \\
\hline Determinações & $\begin{array}{c}\text { Teores } \\
\left(\mathrm{mg}^{\left.-100 \mathrm{~g}^{-1}\right)}\right.\end{array}$ & Determinações & $\begin{array}{c}\text { Teores } \\
\left(\mathrm{mg}^{1} 100 \mathrm{~g} \mathrm{~g}^{-1}\right)\end{array}$ \\
\hline $\mathrm{K}$ & $1.180,00 \pm 1,63$ & $\mathrm{~B}$ & $0,10 \pm 0,02$ \\
$\mathrm{P}$ & $100,00 \pm 0,30$ & $\mathrm{Cu}$ & $5,50 \pm 0,13$ \\
$\mathrm{Ca}$ & $130,00 \pm 0,51$ & $\mathrm{Mn}$ & $4,60 \pm 0,13$ \\
$\mathrm{Mg}$ & $70,00 \pm 0,32$ & $\mathrm{Zn}$ & $533,20 \pm 0,42$ \\
$\mathrm{~S}$ & $100,00 \pm 0,34$ & $\mathrm{Fe}$ & $17,80 \pm 0,38$ \\
$\mathrm{~N}$ & $530,00 \pm 0,75$ & - & - \\
\hline
\end{tabular}

Cada valor foi obtido por meio da média \pm desvio padrão de cinco repetições. que o teor de cálcio em bananas maduras secas varia de 21 a $35,30 \mathrm{mg} .100 \mathrm{~g}^{-1}$ e Alves (1997) relata que em polpa de banana madura o valor médio é de $9 \mathrm{mg} .100 \mathrm{~g}^{-1}$. Comportamento diferente foi constatado por Ascheri et al. (2006) analisando farinha de arroz polido, pois apenas $6,49 \mathrm{mg} \cdot 100 \mathrm{~g}^{-1}$ foi evidenciado. Portanto, constata-se um valor alto de cálcio na farinha de banana verde, equivalente ao observado em farinha de trigo $\left(160 \mathrm{mg} .100 \mathrm{~g} \mathrm{~g}^{-1}\right)$. Conforme Maia et al. (2000), o cálcio participa de várias funções corporais, sendo a estrutural a principal. O alto valor de cálcio constatado credencia a farinha de banana verde como uma rica fonte deste mineral no enriquecimento de alimentos.

A quantidade de magnésio observada neste trabalho foi $70 \mathrm{mg} .100 \mathrm{~g}^{-1}$. Este comportamento corrobora com Medina et al. (1985), quando relatam uma variação de 23,34 a $105 \mathrm{mg} .100 \mathrm{~g}^{-1}$ de magnésio em banana seca. Já Oliveira (1997) trabalhando com farinha de banana madura constatou apenas 25 a $35 \mathrm{mg} .100 \mathrm{~g}^{-1}$, portanto, à medida que a maturação avança, o teor de magnésio no fruto é reduzido. Por outro lado, Ascheri et al. (2006), pesquisando a composição da farinha de arroz polido, verificaram um teor de $54,62 \mathrm{mg} \cdot 100 \mathrm{~g} \mathrm{~g}^{-1}$. Este resultado denota que a farinha de banana verde é uma rica fonte de magnésio, podendo vir a ser utilizada no enriquecimento de alimentos.

$\mathrm{O}$ valor de enxofre evidenciado foi $100 \mathrm{mg} .100 \mathrm{~g}^{-1}$. Comportamento análogo foi obtido por Fernandes (2006), quando trabalhando com farinha de casca de batata registrou um valor de $80 \mathrm{mg} .100 \mathrm{~g} \mathrm{~g}^{-1}$. Por outro lado, Medina et al. (1985) descrevem que a banana madura seca possui apenas $36 \mathrm{mg} .100 \mathrm{~g}^{-1}$ e a polpa de banana madura $12 \mathrm{mg} \cdot 100 \mathrm{~g}^{-1}$.

Para o nitrogênio, o valor médio detectado neste trabalho foi de $530 \mathrm{mg} .100 \mathrm{~g} \mathrm{~g}^{-1}$. Este resultado difere do relatado por Alves (1997) para esta mesma cultivar, quando anuncia um teor de $368 \mathrm{mg} .100 \mathrm{~g} \mathrm{~g}^{-1}$ para polpa de banana madura. Esta diferença pode ser atribuída à diferença de maturação entre as bananas analisadas, pois uma era verde e a outra madura.

O teor de boro averiguado foi $0,1 \mathrm{mg} \cdot \mathrm{kg}^{-1}$, no entanto, Fernandes (2006) trabalhando com farinha de cascas de batata obteve um teor maior $\left(1,48 \mathrm{mg} \cdot 100^{-1}\right)$. Este resultado denuncia que a farinha de banana verde é pobre neste mineral.

O conteúdo de cobre registrado nesse experimento (5,50 mg.100 g $\left.{ }^{-1}\right)$ foi superior ao relatado por Medina et al. (1985), quando anunciaram uma variação de 0,39 a $0,66 \mathrm{mg} \cdot 100 \mathrm{~g}^{-1}$ para banana madura seca e $0,2 \mathrm{mg} .100 \mathrm{~g}^{-1}$ para polpa de banana madura. A discrepância entre o resultado obtido e o observado na literatura é devido à banana estudada estar no estádio verde e a citada na literatura no estádio maduro, portanto, à medida que avança o estádio de maturação da banana, ocorre uma redução no teor de cobre. Este resultado também difere dos de Ascheri et al. (2006), que pesquisando a composição da farinha de bagaço de jabuticaba conseguiram um teor de cobre inferior ao desta pesquisa (1,65 mg.100 g $\mathrm{g}^{-1}$ ).

A quantidade de manganês detectada no ensaio foi $4,60 \mathrm{mg} \cdot 100 \mathrm{~g} \mathrm{~g}^{-1}$. Este resultado é discrepante em relação ao relato de Medina et al. (1985), quando descreveram uma variação no teor manganês de 1,09 a $2,10 \mathrm{mg} \cdot 100 \mathrm{~g}^{-1}$ para banana madura seca e 0,60 mg.100 g ${ }^{-1}$ para polpa de banana madura. Conforme já comentado anteriormente, isto é devido às diferenças nos estádios 
de maturação entre o estudado e a literatura. Neste sentido, Ascheri et al. (2006), pesquisando a composição da farinha de bagaço de jabuticaba e da farinha de arroz polido, obtiveram teores menores (3,36 e $0,81 \mathrm{mg} \cdot 100 \mathrm{~g} \mathrm{~g}^{-1}$, respectivamente) ao desta pesquisa. Já Franco (2000) cita alguns alimentos (aveia e soja) que contêm teores de manganês de 5,00 e 4,10 mg. $100 \mathrm{~g}^{-1}$, respectivamente, portanto, valores próximos aos encontrados neste experimento e consequentemente uma fonte rica deste mineral.

O valor de zinco observado nesta pesquisa foi $533,20 \mathrm{mg} \cdot 100 \mathrm{~g}^{-1}$. $\mathrm{O}$ teor de zinco observado novamente difere do citado por Medina et al. (1985), quando relataram uma variação de apenas 0,43 a $0,69 \mathrm{mg} .100 \mathrm{~g}^{-1}$ para banana madura seca. Portanto, comparando-se os resultados obtidos com os da literatura, constatamos que o teor de zinco é mais sensível ao avanço da maturação. Este resultado denuncia que a farinha de banana verde é rica neste mineral. Neste sentido, Ascheri et al. (2006) avaliando a composição da farinha de bagaço de jabuticaba e da farinha de arroz polido também obtiveram teores bem menores (6,80 e 2,01 mg. $100 \mathrm{~g} \mathrm{~g}^{-1}$, respectivamente) quando comparados a este experimento.

O teor de ferro registrado neste trabalho foi 17,80 mg.100 g-1. Este comportamento difere dos valores de ferro disponíveis na literatura para banana: $1,80 \mathrm{mg} .100 \mathrm{~g}^{-1}$ para banana madura seca e $0,6 \mathrm{mg} .100 \mathrm{~g}^{-1}$ para polpa de banana madura (MEDINA et al., 1985), 0,1 a 0,6 mg.100 g-1 para polpa de banana madura (ALVES, 1997) e 0,02 a 0,03 mg.100 g $\mathrm{g}^{-1}$ para polpa de banana madura (MANICA, 1997). Neste sentido, Rigo (2007) trabalhando com farinha de amêndoa detectou apenas $3,66 \mathrm{mg} .100 \mathrm{~g}^{-1}$, no entanto, Ascheri et al. (2006) trabalhando com farinha de bagaço de jabuticaba e farinha de arroz polido obtiveram 227,23 e 4,26 mg.100 g ${ }^{-1}$, respectivamente.

\subsection{Análises microbiológicas da farinha de banana verde}

Os resultados das análises microbiológicas da farinha de banana verde (coliformes a $45^{\circ} \mathrm{C}$, fungos filamentosos e leveduras, Bacillus cereus, Salmonella sp., Staphylococcus aureus e contagem de aeróbios mesófilos) encontram-se na Tabela 4.

Os resultados microbiológicos obtidos neste trabalho atenderam à legislação da ANVISA - Resolução 12/1978 (ausência em 1 g), pois na contagem microbiológica dos grupos coliformes a $45^{\circ} \mathrm{C}$ ocorrentes na farinha, não se constatou nenhuma bactéria do grupo coliforme de origem fecal.

Com relação aos grupos dos fungos filamentosos e leveduras o valor encontrado foi $<10$ UFC. $\mathrm{g}^{-1}$, portanto, considerado dentro do padrão, pois, conforme a ANVISA - Resolução CNNPA $\mathrm{n}^{\circ} 12$ de 1978, o padrão máximo de bolores e leveduras é de $10^{3} \cdot \mathrm{g}^{-1}$. Indicando assim que, durante o processamento das bananas para obtenção da farinha utilizaram-se boas práticas de fabricação. De acordo com Almeida et al. (2007), ao avaliar a vida útil de prateleira da farinha de mandioca, constataram que após um armazenamento de 180 dias a farinha apresentou um baixo nível de colônias de bolores e leveduras (dados não apresentados).
Tabela 4. Valores médios de coliformes a $45^{\circ} \mathrm{C}$, fungos filamentosos e leveduras, Bacillus cereus, Salmonella sp., Staphylococcus aureus e contagem de aeróbios mesófilos da farinha de banana verde, cv. Prata e os valores padrões na ANVISA.

\begin{tabular}{lcc}
\hline \multicolumn{1}{c}{ Microrganismos } & Valores médios & Padrões da ANVISA \\
\hline Coliforme à $45^{\circ} \mathrm{C}\left(\mathrm{NMP}^{-1}\right)$ & $<3$ & Ausência em $1 \mathrm{~g}$ \\
$\begin{array}{l}\text { Fungos filamentosos e } \\
\left.\text { leveduras (UFC. } \mathrm{g}^{-1}\right)\end{array}$ & $<10$ & $10^{3} \cdot \mathrm{g}^{-1}$ \\
Bacillus cereus $\left(\mathrm{UFC} \cdot \mathrm{g}^{-1}\right)$ & $<10$ & $10^{3} \cdot \mathrm{g}^{-1}$ \\
Salmonella sp. $(25 \mathrm{~g})$ & Ausência & Ausência em $25 \mathrm{~g}$ \\
$\begin{array}{l}\text { Staphylococcus aureus }\left(\mathrm{UFC} \cdot \mathrm{g}^{-1}\right) \\
\text { Contagem de aeróbios }\end{array}$ & $<10$ & Ausência em $0,1 \mathrm{~g}$ \\
mesófilos (UFC. $\left.\mathrm{g}^{-1}\right)$ & $<10$ & $5 \times 10^{5} \cdot \mathrm{g}^{-1}$ \\
\hline
\end{tabular}

Para a análise de Bacillus cereus não foi encontrada nenhuma contaminação. O limite máximo segundo a ANVISA Resolução $12 / 1978$ é de $10^{3} \cdot \mathrm{g}^{-1}$.

A Salmonella sp. não apresentou nenhum crescimento na farinha, atendendo, portanto, à legislação vigente, pois o limite conforme a ANVISA - Resolução 12/1978 é ausência em $25 \mathrm{~g}$.

Quanto à análise de Staphylococcus aureus, o resultado apresentado também está dentro do padrão $\left(<10\right.$ UFC. $\left.{ }^{-1}\right)$, assegurando a qualidade do produto. O limite segundo a ANVISA - Resolução 12/1978 é de ausência em 0,1 g. Neste mesmo sentido, Ferreira Neto et al. (2004), em experimento com armazenamento de farinha de mandioca por 180 dias, também encontraram ausência de Staphylococcus aureus.

A contagem de aeróbios mesófilos apresentou um índice $<10$ UFC. $\mathrm{g}^{-1}$. Portanto, atende à Resolução 12/1978 da ANVISA, pois o limite máximo de contagem padrão em placas é de $5 \times 10^{5} \cdot \mathrm{g}^{-1}$. Por outro lado, Ferreira Neto et al. (2004), em experimento de armazenamento com farinha de mandioca encontraram mesófilos dentro do padrão segundo a Legislação do Ministério da Agricultura (BRASIL, 1997).

\section{Conclusões}

Mediante os parâmetros analisados podemos concluir que a farinha de banana verde é uma rica fonte de amido e proteína, podendo também substituir outras fontes de alimentos por ter um alto valor calórico.

De acordo com as características físico-químicas, a farinha de banana verde encontra-se com seu teor de $\mathrm{pH}$, acidez total titulável e vitamina $\mathrm{C}$ dentro dos limites, quando comparada com outras fontes de farinhas encontradas no mercado.

Quanto ao conteúdo de minerais, a farinha de banana verde é uma rica fonte de potássio, fósforo, magnésio, cobre, manganês e zinco, quando comparada aos demais tipos de farinhas existentes no mercado.

Microbiologicamente, quanto ao processo de obtenção da farinha de banana verde, quando comparado com os demais processos de obtenção, a farinha encontra-se dentro do padrão microbiológico ideal e, portanto, está apta para o consumo. 
A banana verde, cultivar Prata é viável para o processo de obtenção da farinha de banana verde, visando o enriquecimento dos alimentos ou a substituição parcial da farinha de trigo, podendo ser utilizada em panificação, confeitaria, alimentos infantis e produtos dietéticos.

\section{Referências bibliográficas}

ADÃO, R. C.; GLÓRIA, M. B. A. Bioactive amines and carboydrate changes during repening of Prata banana (Musa acuminata $\times$ M. balbisiana). Food Chemistry, v. 90, n. 4, p. 705-711, 2005.

AGÊNCIA NACIONAL DE VIGILÂNCIA SANITÁRIA - ANVISA. Resolução CNNPA n. 12 de 1978. Diário Oficial da União, Brasília, 24 de Julho de 1978. Disponível em: <http://www.anvisa.gov.br>. Acesso em: 16 de Fevereiro de 2007.

ALMEIDA, G. M. et al. Qualidade da farinha de mandioca produzida em Alcântara Maranhão. In: CONGRESSO BRASILEIRO DE MANDIOCA, 11, 2005, Campo Grande. Anais... Campo Grande: Secretaria de Ciência e Tecnologia do Mato Grosso do Sul, 2005. Disponível em: <http://www.suct.ms.gov.br/mandioca/trabalhos/ pasta60.pdf $>$. Acesso em: 20 de Agosto de 2007.

ALVES, E. J. (Org.). A cultura da banana: aspectos técnicos, socioeconômicos e agroindustriais. Brasília: Embrapa-SPI; Cruz das Almas: Embrapa-CNPMF, 1997. 585 p.

AMERICAN PUBLIC HEALTH ASSOCIATION - APHA. Compendium of methods for the microbiological examination of foods. Washington, 2001.316 p.

ASCHERI, D. P. R.; ASCHERI, J. L. R.; CARVALHO, C. W. P. Características da farinha de bagaço de jabuticaba e propriedades funcionais dos extrusados. Ciência e Tecnologia de Alimentos, v. 26, n. 4, p. 897-905, 2006.

ASSOCIATION OF OFFICIAL ANALYTICAL CHEMISTS - AOAC. Official methods of analysis. Arlington, 1995. $1141 \mathrm{p}$.

BORBA, A. M. Efeitos de alguns parâmetros operacionais nas características físicas e físico-químicas e funcionais de extrusados da farinha de batata doce (Ipomoea batatas). 2005. $115 \mathrm{f}$. Dissertação (Mestrado em Ciências) - Universidade de São Paulo, Piracicaba, 2005.

BRASIL. Ministério da Saúde. Agência Nacional de Vigilância Sanitária ANVISA. Portaria SVS n. 451 de 19 de setembro de 1997. Aprova o regulamento técnico princípios gerais para o estabelecimento de critérios e padrões microbiológicos para alimentos e seus anexos. Diário Oficial da República Federativa do Brasil, Poder Executivo, Brasília, 22 de Setembro de 1997.

CARVALHO, R. V. Formulações de snacks de terceira geração por extrusão: caracterização texturométrica e microestrutural. 2000. $89 \mathrm{f}$. Dissertação (Mestrado em Ciência dos Alimentos) - Universidade Federal de Lavras, Lavras, 2000.

CHISTÉ, R. C. et al. Qualidade da farinha de mandioca do grupo seca. Ciências Tecnologia de Alimentos, v. 26, n. 4, p. 861-864, 2006.

DAMIANI, C. R. Avaliação nutricional e aceitabilidade de alimentos formulados utilizados em programas institucionais. 1989. $79 \mathrm{f}$. Dissertação (Mestrado em Ciência e Tecnologia de Alimentos) Universidade Federal de Viçosa, Viçosa, 1989.

FERNANDES, A. F. Utilização da farinha de casca de batata inglesa (Solanum tuberosum L.) na elaboração de pão integral. 2006. $127 \mathrm{f}$. Dissertação (Mestrado em Ciência dos Alimentos) - Universidade Federal de Lavras, Lavras, 2006.
FERREIRA NETO, C. et al. Microbiologia de farinhas de mandioca (Manihot esculenta Crantz) durante o armazenamento. Ciência Rural, v. 34, n. 2, p. 551-555, 2004.

FONTES, L. C. B. Uso de solução conservadora e de película comestíveis em maçãs da cultivar Royal gala minimamente processada: efeito na fisiologia e na conservação. 2005. 132 f. Dissertação (Mestrado em Ciência e Tecnologia de Alimentos) - Universidade de São Paulo, Piracicaba, 2005.

FRANCO, G. Tabela de composição química dos alimentos. São Paulo: Atheneu, 2000. 307 p.

INSTITUTO ADOLFO LUTZ. Normas analíticas, métodos químicos e físicos para análise de alimentos. São Paulo, 1985. 533 p.

KAMER, J. H.; GINKEL, L. V. Rapid determination of crude fiber in cereais. Cereal Chemistry, v. 29, n. 4, p. 239-251, 1952.

LOURES, A. Obtenção, caracterização e utilização de farinha de banana (Musa spp.) em panificação. 1989. 132 f. Dissertação (Mestrado em Farmácia) - Universidade Federal de Minas Gerais, Belo Horizonte, 1989.

LUCENA, E. M. P. et al. Uso de etileno exógeno na maturação da banana 'Prata-anã. In: INTERAMERICAN SOCIETY FOR TROPICAL HORTICULTURE, 2003, Miami. Proceedings... Fortaleza: ISTH, 2003. p. 125-128.

MAIA, L. H. et al. Características químicas dos mingaus desidratados de arroz e soja. Ciências e Tecnologia de Alimentos, v. 20, n. 3, p. 416-423, 2000.

MALAVOLTA, E.; VITTI, G. C.; OLIVEIRA, S. A. Avaliação de estado nutricional de plantas. Piracicaba: Potafos, 1989. 201 p.

MANICA, I. Fruticultura tropical 4: banana. Porto Alegre: Cinco Continentes, 1997. 485 p.

MEDINA, J. C. et al. Banana: cultura, material-prima, processamento e aspectos econômicos. Campinas: ITAL, 1985. 302 p.

MILLER, G. L. Use of dinitrosalicylic acid reagent for determination of reducing sugars. Analytical Chemistry, v. 31, n. 3, p. 426-428, 1959.

MORAES NETO, J. M. et al. Componentes químicos da farinha de banana (Musa spp.) obtida por meio de secagem natural. Revista Brasileira de Engenharia Agrícola e Ambiental, v. 2, n. 3, p. 316-318, 1998.

OLIVEIRA, D. A. G. Avaliação química, nutricional e sensorial de uma mistura à base de farinhas de arroz, banana e mandioca, enriquecida com outras fontes protéicas. 1997. 79 f. Dissertação (Mestrado em Agronomia) - Universidade de São Paulo, Piracicaba, 1997.

OSBORNE, D. R.; VOOGT, P. The analysis of nutrient in foods. London: Academic Press, 1978. 251 p.

PACHECO-DELAHAYE, E.; TESTA, G. Evaluación nutricional, física y sensorial de panes de trigo y plátano verde. Interciencia, v. 30, n. 5, p. 300-304, 2005.

PEARSON, D. The chemical analysis of foods. New York: First American, 1971. 149 p.

PEREIRA, C. A. et al. Utilização de farinha obtida a partir de rejeito de batata na elaboração de biscoitos. Ciência Agronômica de Engenharia, v. 11, n. 1, p. 19-26, 2005.

RIGO, N. Farinha de Amêndoa. São Paulo: Editora CARAS, 2006. Disponível em: $<$ http://caras.uol.com.br/cozinha/cozinha_39htm $>$. Acesso em: 4 de Março de 2007.

SARRUGE, J. R. R.; HAGG, H. P. Análise química em plantas. Piracicaba: ESALQ/USP, 1974. 56 p.

SISTEMA BRASILEIRO DE RESPOSTAS TÉCNICAS - SBRT. Rio de Janeiro: Ministério da Ciência e Tecnologia, 2005. Disponível em: <http://sbrt.ibict.br/upload/sbrt 424.pdf>. Acesso em: 22 de Agosto de 2006. 
SOUSA, P. H. M. et al. Influência da concentração e da proporção fruto: xarope na desidratação osmótica de bananas processadas. Ciência e Tecnologia Alimentos, v. 23 (supl), p. 126-130, 2003.

TORRES, L. G. et al. Efeito da umidade e da temperatura no processamento de farinha de banana verde (Musa acuminata, grupo AAA) por extrusão termoplástica. Boletim da Sociedade Brasileira de Ciência e Tecnologia de Alimentos, v. 23, n. 2, p. 273-290, 2005.
VILAS BOAS, E. V. B. et al. Características da fruta. In: MATSUURA, F. C. A. U.; FOLEGATTI, I. S. (Eds.). Banana: pós-colheita. Brasília: Embrapa Informação Tecnológica, 2001. p. 15-19.

YAMASHITA, F. et al. Produtos de acerola: estudo da estabilidade de vitamina C. Ciência e Tecnologia de Alimentos, v. 23, n. 1, p. 92-94, 2003. 